\title{
Function and Application of Geogrid in Flexible Pavement under Dynamic Load
}

\author{
Fatin F. Jebur*, Mohammed Y. Fattah ${ }^{\mathbb{D}}$, Ahmed S. Abduljabbar \\ Civil Engineering Department, University of Technology, Baghdad, Iraq. \\ *Corresponding author Email: fatenfaraj1995@gmail.com
}

\section{H I G H L I G H T S}

- A laboratory model experiments to understand the behavior of subgrade under dynamic load

- Reinforcement is applied at the interface between the base and subgrade layers.

- Layers are exposed to harmonic dynamic load with two amplitudes and two frequencies.

- The vertical stresses in the road layers are measured using stress gauge sensor.

- Stress decreases by increasing frequency and load amplitudes by about (23-42)\%.

A R T I C L E I N F O

Handling editor: Wasan I. Khalil

\section{Keywords:}

Base course

Vertical displacement

Flexible pavement

Geogrid reinforcement

Stresses transmission

\begin{abstract}
A B S T R A C T
Nowadays, the increasing demand for road transport makes maintenance and repair of road infrastructures key tasks for road engineering. The current experimental work consists of laboratory model experiments to understand the conduct of sand as a subgrade under dynamic load and its effect on the flexible pavement and base layer. The reinforcement is applied at the interface between the base and subgrade using SS2 type of geogrid. The road layers are exposed to harmonic dynamic load with two load amplitudes 10 and $15 \mathrm{kN}$ and two frequencies 0.5 and $1 \mathrm{~Hz}$. The vertical stresses in the road layers are measured using stress gauge sensor. In the case of a reinforcing geogrid at the middle of base course, the stress decreases by increasing the frequency and load amplitudes by about (23-42). The best position for geogrid is in the middle of crushed stone layer because it gives lower displacement. In the case of a reinforcing layer at the middle of base course layer, the stress and vertical displacement decrease with increase in frequency and load amplitudes. When laying the geogrid between the base course and subgrade, a lower decrease in the stress and vertical displacement could be obtained with the increase in frequency and loads.
\end{abstract}

\section{Introduction}

Dynamic axle loads have different effect other than their static values, i.e., those obtained with the vehicle stopped at a truck inspection station. This is due to the dynamic interaction between vehicles and pavement, which induces the activity of vehicle frame and axles. The resulting dynamic axle loads are affected by number of factors such as pavement roughness, vehicle operating speed, and axle suspension type. As presented in [1] where the researchers pointed out that the most effective position of the geosynthetic is at the interface of the granular material and the subgrade surface. In this position, the geosynthetic provides separation, lateral restraint of the upper granular course. Chen, [2] investigated the potential of using the reinforcement to lessen the settlement of shallow foundations and improve the bearing capacity. A total of one hundred seventeen tests were conducted to investigate the behavior of reinforced soil foundation. The study results showed that the inclusion of reinforcement can substantially reduce the footing settlement and improve the soil's bearing capacity. The test results show that the presence of geogrid distributes loads to a wider zone, this leads to a decrease stress concentricity and stress can be distributed evenly. Redistribution of stresses beneath the reinforced area leads to minimizing the consolidation adjustment of the underlying weak clayey soil. [3] reported the results of instrumented pavement(with and without fiber glass geogrids within the asphalt layer) as a section of a large-scale pavement study. The inclusion of geogrids was found to lead to a decrease in vertical displacements of approximately $38 \%$, as well as a reduction in vertical stresses in the underlying layers.[4] he was found that the use of geogrid leads to increase the strength of California Bearing Ratio (CBR), tests were conducted on soil with geo-grid put at various profundity within the sample, at single, double, and triple layer, it was 
concluded that placing geogrid at a distance of $2 / 3$ from the base gives the best performance. After studying the effect of presence, the geotextile between subgrade and base it was found that with an increase in the geotextile layer, the penetration resistance increased [5].

A physical model including all pavement structure layers was built by [6]. The main research objective is to measure the elastic deformation, stresses, and permanent deformations at variable depths. Both physical and experimental mode results are close enough. Furthermore, both stresses and elastic deformations were studied using different properties of the structure using algorithmic calculations. [7] have studied the structural response of geogrid reinforced asphalt overlays, their main focus on observing the strains within the asphalt layer. Results of their study showed an overall decrease of $65 \%$ in peak tensile strains in the reinforced part when compared with unreinforced section. An experimental investigation was conducted by [8]to investigate the shape of footing's impact, when rested upon clayey soil under cyclic loading condition. It was observed that the bearing capacity varies in increasing order as solid circular and square. The cyclic settlement in circular footing can be higher than the square footing. The present study has multiple objectives. The first objective is to identify critical geogrid characteristics that effects of flexible pavement performance. The second objective is to estimate the effect of geogrid location on the flexible pavement performance. Final objective is to study the effect of different values and frequencies of dynamic load on induced strains and stresses between flexible pavement layers reinforced with geogrids.

\section{Experimental Work}

\subsection{Materials}

The soil utilized in this research as a subgrade layer is sand which brought from Karbala in Iraq. Several physical tests were conducted on it, the soil is classified as SP-SM soil according to the Unified Soil Classification System USCS. The base was selected from Al-Nibaie quarry, north of Baghdad city. This type of base is usually applied as a layer in flexible pavement construction the physical and chemical properties are (sieve analysis, flat and elongation, angularity, toughness by (Los Angeles abrasion), specific gravity, soundness, in addition to equivalent sand (clay content)One type of asphalt was used which is AC (40 -50) from Daurah refinery.Several physical properties tests were conducted as illustrated in Table1.

\subsection{Pavement layer preparation}

A slab of square section $(30 \mathrm{~cm} * 30 \mathrm{~cm})$ and $5 \mathrm{~cm}$ thickness as shown in Figure 1 . The weight of the asphalt mixture was calculated to be 10522.4 gm at optimum asphalt content $5.25 \%$. The asphalt mixture is put uniformly in the steel mold by using heated spatula then it is put in the slightly oiled surface of the mold. After that, the surfaces are leveled. The utilized compression static load of 10 ton is maintained for 6 minutes to achieve the same value of Marshall Specimen's bulk density which is equal to $2.32 \mathrm{~kg} / \mathrm{m} 3$.

\subsection{Preparation of asphalt concrete mixture}

Marshal method is utilized to prepare the asphalt mixture slabs. Asphalt mixture slabs are mixed and compacted at asphalt temperatures which are identical to viscosity of $0.17 \pm 0.02$ and $0.28 \pm 0.03$ Pascal-seconds, respectively [9].

\subsection{Thickness of the model layers}

The thickness of the selected layers relies on several research associated with this study. The thickness of subgrade is selected based on the work of [10,11]which is $600 \mathrm{~mm}$. The thickness of the base layer is $150 \mathrm{~mm}$ while the asphalt layer is 50 $\mathrm{mm}$.

\subsection{Geogrid reinforcement}

The geogrid reinforcement selected in the present work is SS2 geogrid, it is produced by QMOF CO (Quality Material of Oil Field) company as shown in Figures 3 and 4.

\subsection{Unreinforced models}

At the beginning, the sand is poured in the steel container, and then sensor was placed at depth of $5 \mathrm{~cm}$ from the surface of the sand and compacted by a steel hammer and leveled. Next, the base layer is placed above the subgrade. The second sensor is placed at a depth of $5 \mathrm{~cm}$ from the middle of the base course layer thickness. Asphalt layer is placed above the base. The third sensor is placed on a thin plate which is placed directly under the asphalt layer as shown in Figure 5.

\subsection{Reinforced models}

After the elaboration of sand soil, the SS2 geogrid layer is laid over the subgrade layer. Next, the base course layer is placed on the geogrid layer. Then the pavement slab is put on the box center. This is considered as a test, and then the procedure is repeated with changing the geogrid location to the middle of the base layer as shown in Figure 6 .

\subsection{Load application apparatus}

To simulate the dynamic load in the laboratory applied on pavement layers, a vibration loading device was utilized. The device was developed by [13]. An electric air compressor with maximum load amplitude of (12 kN) was used. The loading amplitude was increased to $(60 \mathrm{kN})$ throughout device modification developed by [13]. The device consists of the following parts as shown in Figure 7:1. Steel loading frame. 2. Hydraulic loading system. 3. Load spreader beam.4. Data acquisition.5. 
Shaft encoder. 6. Steel container. The device adopts a dynamic load of half sine wave shape (only positive). Pressure sensors that are capable of measuring the stresses while the vertical surface displacements of the pavement system are monitored by the device.

\section{Stress Results for Unreinforced Models}

Figures 8to 11 present the stresses transmitted to the asphalt layer and underlying base and subgrade layers using $150 \mathrm{~mm}$ base course thickness with two load amplitudes: 10 and $15 \mathrm{kN}$ and two frequencies $0.5 \mathrm{and} 1 \mathrm{~Hz}$. It can be observed that there is a decrease in the vertical stress with increased frequency from 0.5 to $1 \mathrm{~Hz}$ when the load amplitude is $10 \mathrm{kN}$, but when increasing the load amplitude to $15 \mathrm{kN}$, the vertical stress decreases.

\section{Stress Results For Reinforced Models}

Figures 12 to 19 showing the results of a reinforcing layer at the mid of the base course, when the load amplitude is $10 \mathrm{kN}$ and the frequency is $1 \mathrm{~Hz}$.

* Stress results for reinforced models, SS2 type of geogrid is used at the midst of crushed stone layer.

Figure (12) illustrates the relationship between vertical stress and time, when the frequency is $0.5 \mathrm{~Hz}$ and load amplitude $10 \mathrm{kN}$ the maximum stress is reduced by $40.2 \%$.

When increasing the frequency to $1 \mathrm{~Hz}$ and load amplitude is $10 \mathrm{kN}$, it is noticed that the presence of reinforcement reduces the maximum stress by $23.5 \%$.

When increasing the load amplitude to $15 \mathrm{kN}$ and the frequency is $0.5 \mathrm{~Hz}$, the maximum stress is reduced by $42.8 \%$.

But when increasing frequency to $1 \mathrm{~Hz}$ and the load is $15 \mathrm{kN}$, the maximum stress is reduced by $35.4 \%$.

The presence of geogrid reinforcement in the middle of base course layer reduces the transmitted stresses by about 23.5 $42.8 \%$ depending on the load amplitude and frequency.

The presence of geogrid limits the lateral displacement of the reinforcing layer which is approximately $5 \mathrm{~cm}$ on and under the geogrid as concluded by Leshchinsky and Ling (2013)[14]. The geogrid also improves the performance of the road structure is improved through the total confinement of aggregate to the unpaved base.

Fattah et al. (2019) [15] showed that the presence of one or more layers of geogrid at the bottom of the base allows for the shear interaction between the aggregate and the geogrid, as the base attempted to spread laterally. Shear load was transmitted from the base aggregate to the geogrid and placed the geogrid in tension. The relatively high stiffness of the geogrid acted to retard the development of lateral tensile strain in the base adjacent to the geogrid. Lower lateral strain in the base resulted in less vertical deformation of the railway surface. Hence, the first mechanism of reinforcement corresponds to direct prevention of lateral spreading of the base aggregate.

Geogrid gives better interlocking between it and soil particles. An improvement in the load bearing capacity can refer to the dispersion of the loads through the reinforced base to the lower layer. As a result, the stresses that are transferred to the subgrade are reduced.

* Stress results for reinforced models, SS2 type of geogrid used between base layer and subgrade

After placing the geogrid over sand and the load amplitude is $10 \mathrm{kN}$ and the frequency $0.5 \mathrm{~Hz}$, the presence of geogrid reduces the maximum vertical stress by $39.4 \%$ compared to unreinforced case as shown in Figure 16.

Figure (17), when increasing the frequency to $1 \mathrm{~Hz}$ and load amplitude $10 \mathrm{kN}$, the maximum stress is reduced by $20.4 \%$.

The maximum stress is reduced by $35.5 \%$, when increasing load amplitude to $15 \mathrm{kN}$ as shown in Figure 18 , But when increasing the frequency to $1 \mathrm{~Hz}$ and load amplitude $15 \mathrm{kN}$, the maximum stress is reduced by $31.5 \%$ as shown in Figure 19 .

On the other hand, inserting geogrid mesh in the interface between the subgrade and base layers reduces the stress transmitted by about $20.4-39.4 \%$.

\section{Displacement Results for Unreinforced Models}

In this study, the vertical displacement of the pavement layers is measured at the surface of asphalt layer. From Figures 19 to 22 , it is noticed that there is an increase in the displacement associated with frequency increase from 0.5 to $1 \mathrm{~Hz}$.

The presents results agree with the findings in [16]where researchers concluded that that the factors that helped increase the load under the base are the increase in dynamic force, operating frequency, and degree of saturation. Meanwhile, it is decrease with rising the relative density of sand, modulus of elasticity and embedding inside soils.

\section{Displacement Results for Reinforced Models}

*Displacement results for reinforced models, SS2 type of geogrid used in the middle of base layer

Figure 24 shows the relationship between displacement and time. When the frequency is $0.5 \mathrm{~Hz}$ and load amplitude is 10 $\mathrm{kN}$, the displacement decreases by $84.5 \%$.

Increasing the frequency to $1 \mathrm{~Hz}$ leads to reduce the maximum displacement by $57.9 \%$, when the load amplitude is $10 \mathrm{kN}$ as shown in Figure 25.

But when increasing the load amplitude to $15 \mathrm{kN}$, and the frequency is 0.5 , the displacement increased by $37.4 \%$ as shown in Figure 26.

When the load is $15 \mathrm{kN}$ and the frequency is $1 \mathrm{~Hz}$, the displacement is reduced by $32.4 \%$ as shown in Figure 27.

* Displacement results for reinforced models, SS2 type of geogrid used between base layer and subgrade

After that, when changing the position of geogrid and putting the reinforced layer over sand, the maximum displacement decreases by $62.7 \%$ under a load amplitude $10 \mathrm{kN}$ and $0.5 \mathrm{~Hz}$ frequency, as shown in Figure 28. 
But when the frequency is $1 \mathrm{~Hz}$, and load amplitude $10 \mathrm{kN}$, the displacement decreases by $46.7 \%$ as shown in Figure 29 .

Figure 30shows that the maximum displacement increases by $12.7 \%$, when increasing the load amplitude to $15 \mathrm{kN}$ and frequency is $0.5 \mathrm{~Hz}$. The vertical displacement increases with the load amplitude[17].

When increasing the frequency to $1 \mathrm{~Hz}$, and load amplitude $15 \mathrm{kN}$, it is noticed that there is a small decrease in displacement by $3.2 \%$ as shown in Figure (31).[18] found that the vertical settlement in loose sand is reduced by about $20 \%$ when using geogrid reinforcement at a depth equals to $(0.5 \mathrm{~B})$. Also, at depth equal to $(1 \mathrm{~B})$, the vertical settlement is reduced by about $13 \%$. In addition, when the geogrid is placed at a depth equals to (1.5B), the results of vertical settlement without geogrid are approximately close to results of vertical settlement with geogrid.

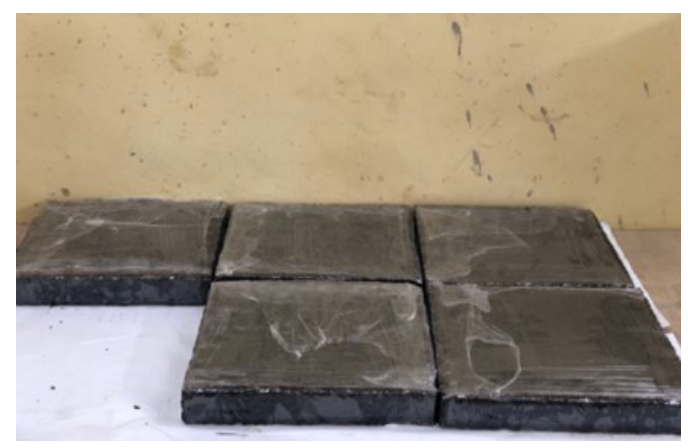

Figure 1: Slab models covered with Polyethylene

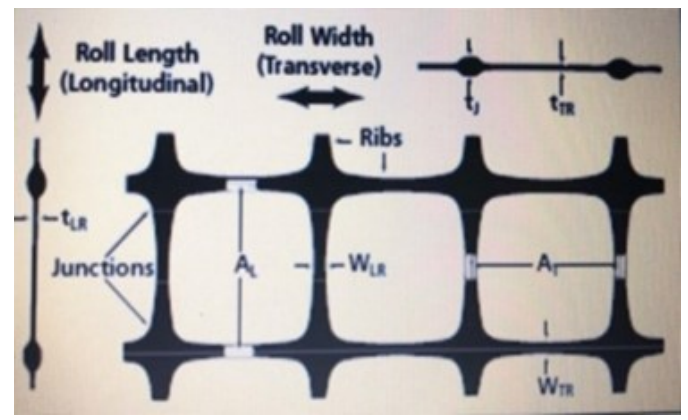

Figure 3: Used geogrid dimension details

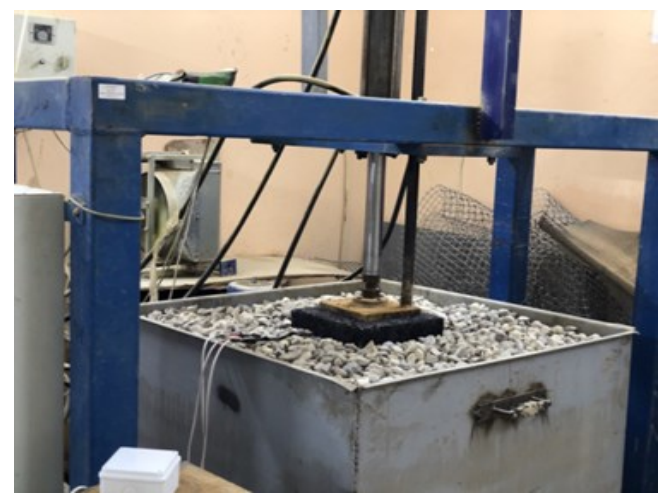

Figure 5: Unreinforced models

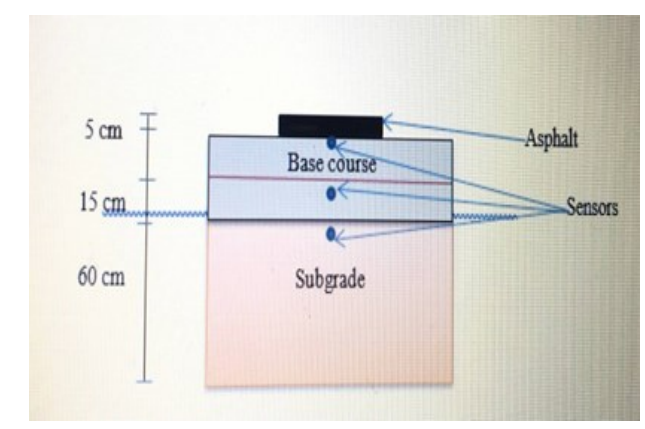

Figure 2: Thickness of the model layers

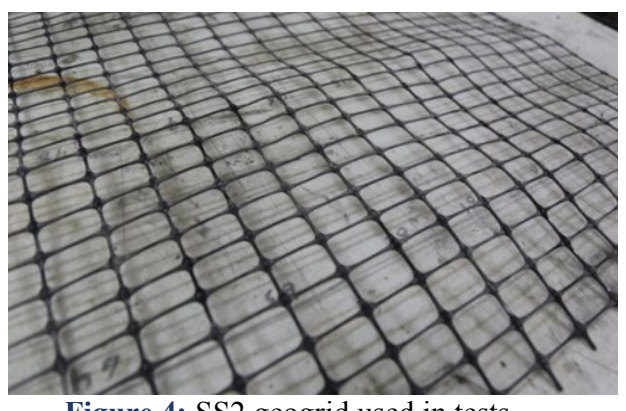

Figure 4: SS2 geogrid used in tests

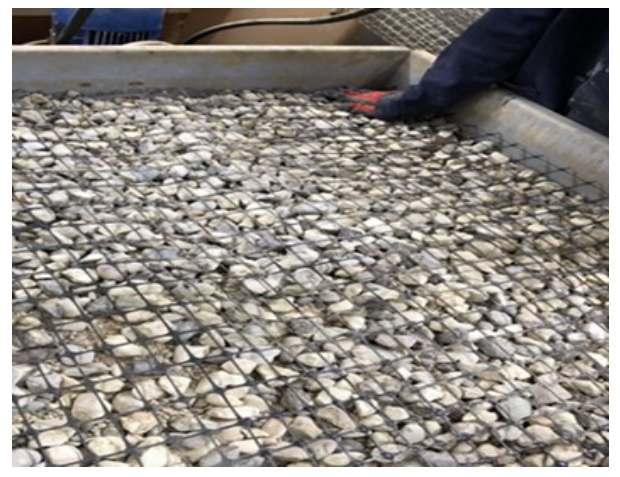

Figure 6: Base reinforced with geogrid

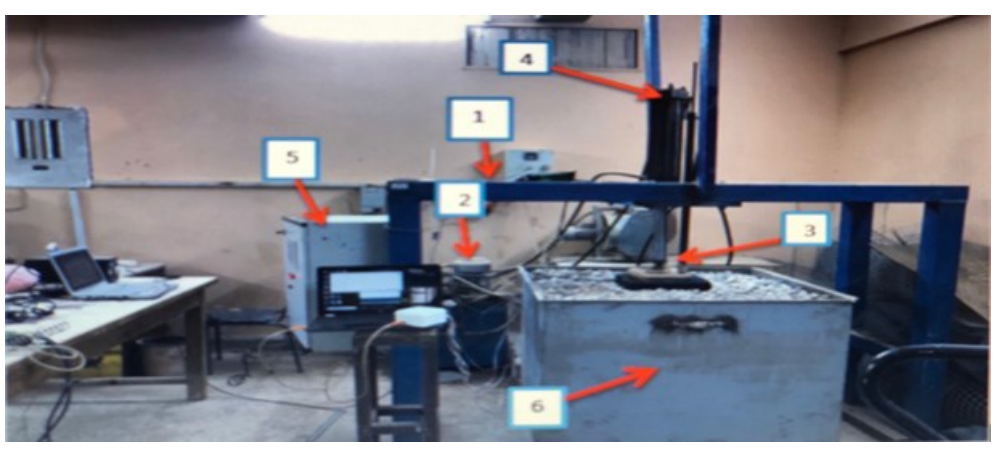

Figure 7: The device used in experimental work 


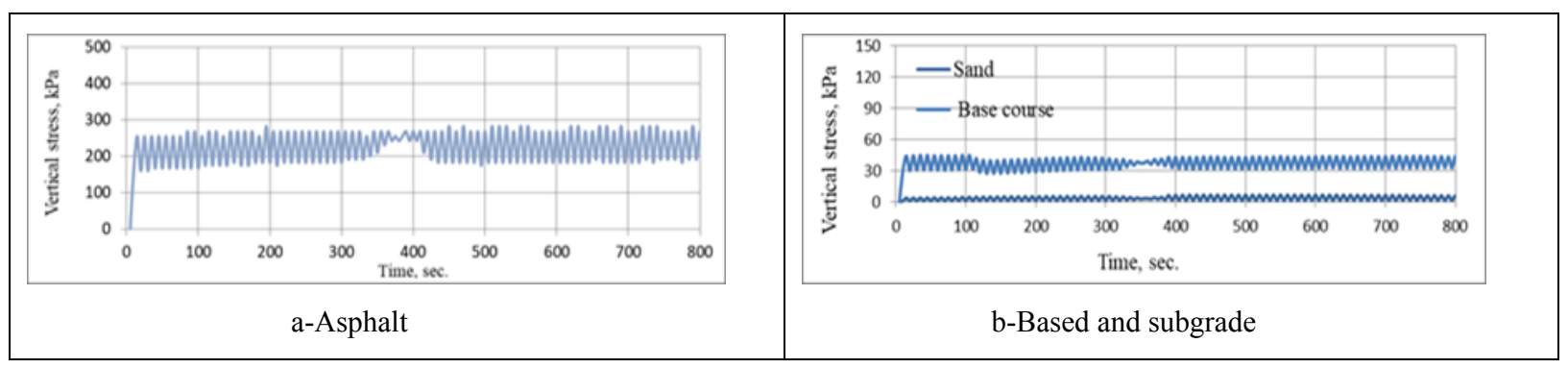

Figure 8: Variation of vertical stress in road layers under a frequency $1 \mathrm{~Hz}$ and load amplitude $10 \mathrm{kN}$

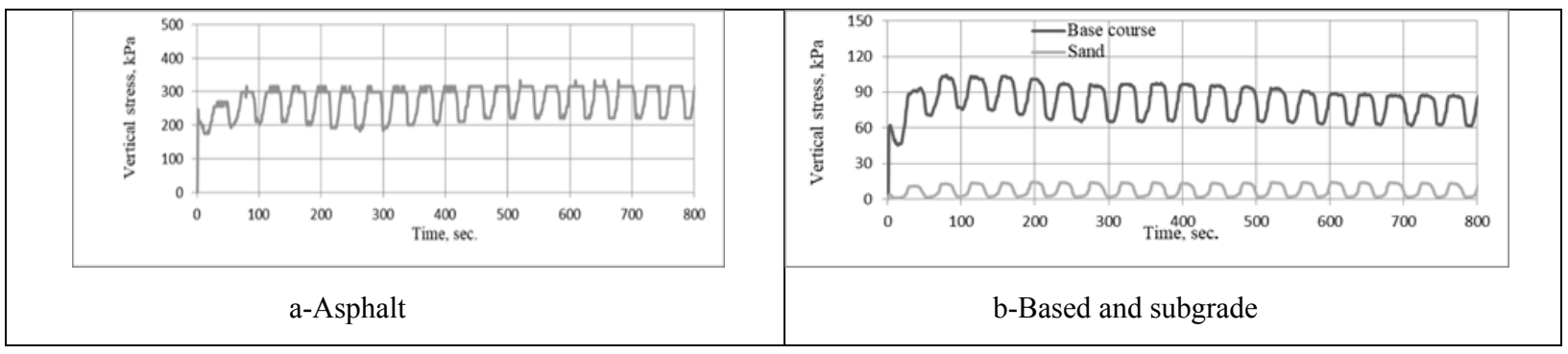

Figure 9: Variation of vertical stress in road layers under a frequency $0.5 \mathrm{~Hz}$ and load amplitude $10 \mathrm{kN}$

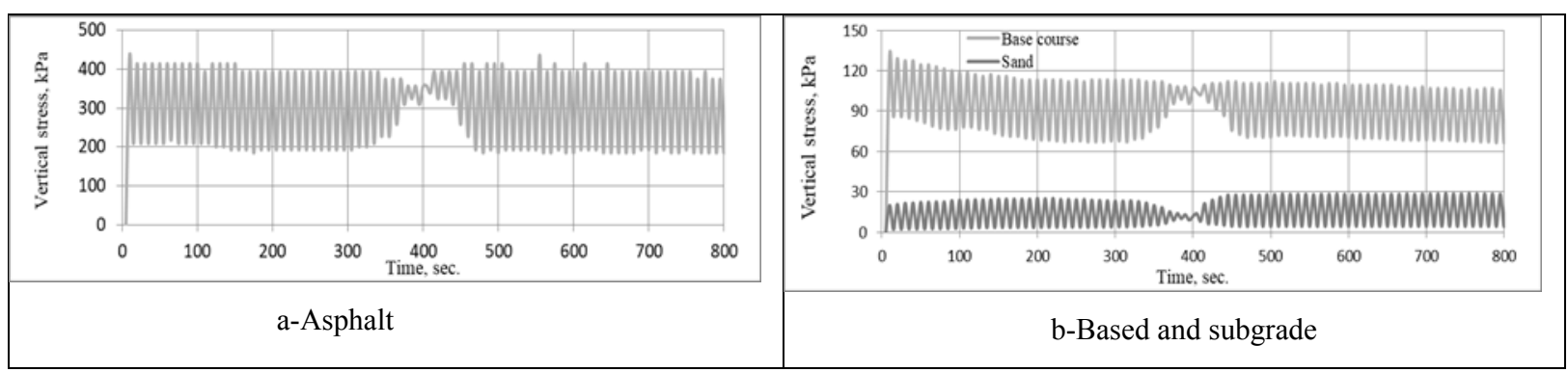

Figure 10: Variation of vertical stress in road layers under a frequency $1 \mathrm{~Hz}$ and load amplitude $15 \mathrm{kN}$
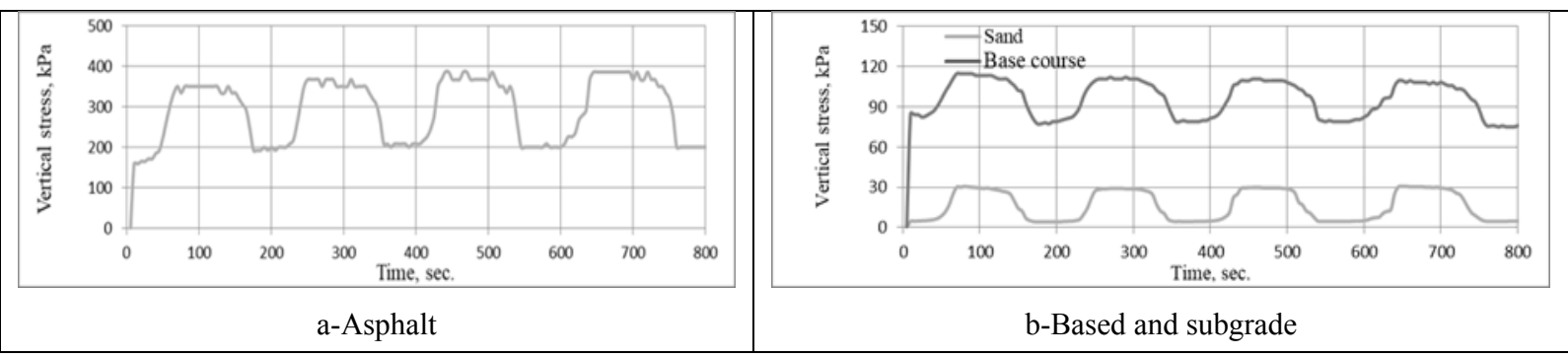

Figure 11: Variation of vertical stress in road layers under a frequency $0.5 \mathrm{~Hz}$ and load amplitude $15 \mathrm{kN}$

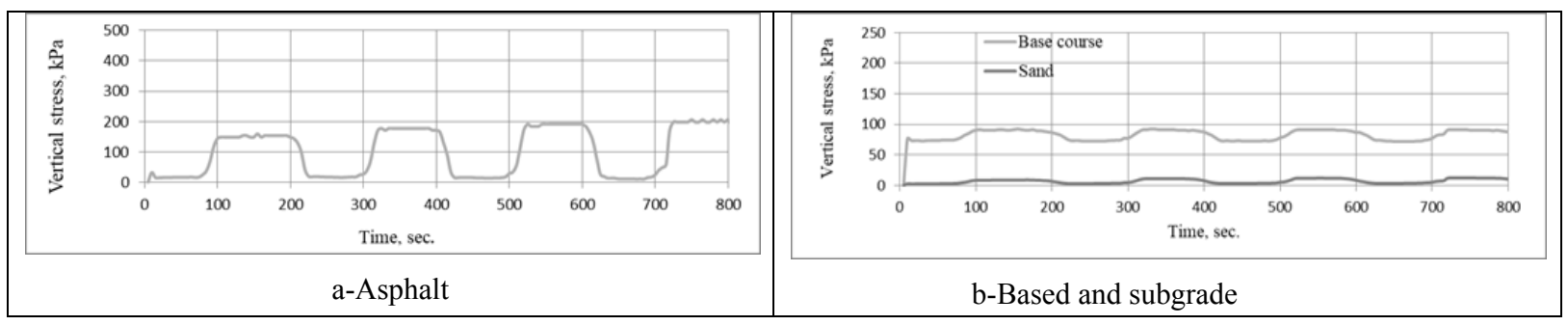

Figure 12: Variation of vertical stress in road layers under a frequency $0.5 \mathrm{~Hz}$ and load amplitude 10 $\mathrm{kN}$, geogrid in the midst of crushed stone layer. 


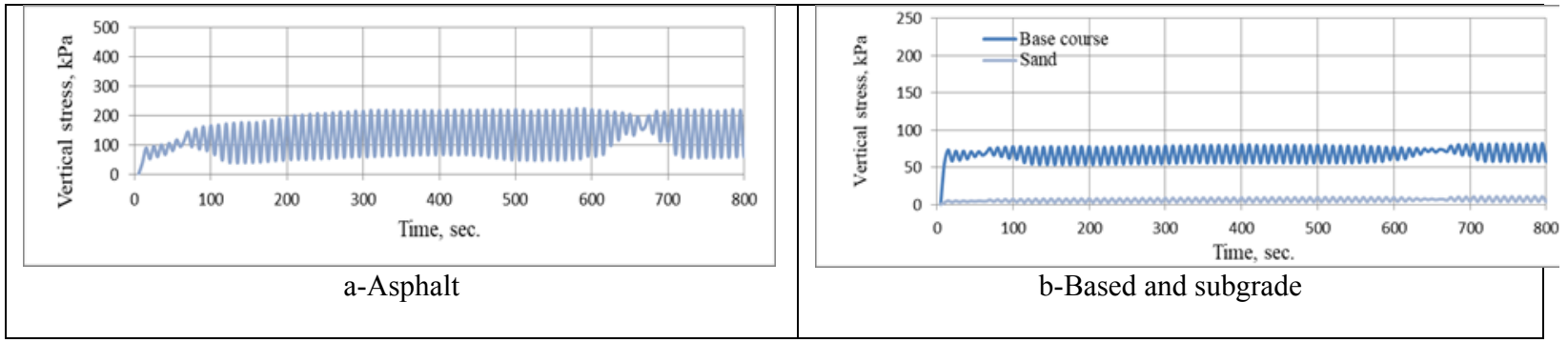

Figure 13: Variation of vertical stress in road layers under a frequency $1 \mathrm{~Hz}$ and load amplitude 10 $\mathrm{kN}$, geogrid in the midst of crushed stone layer
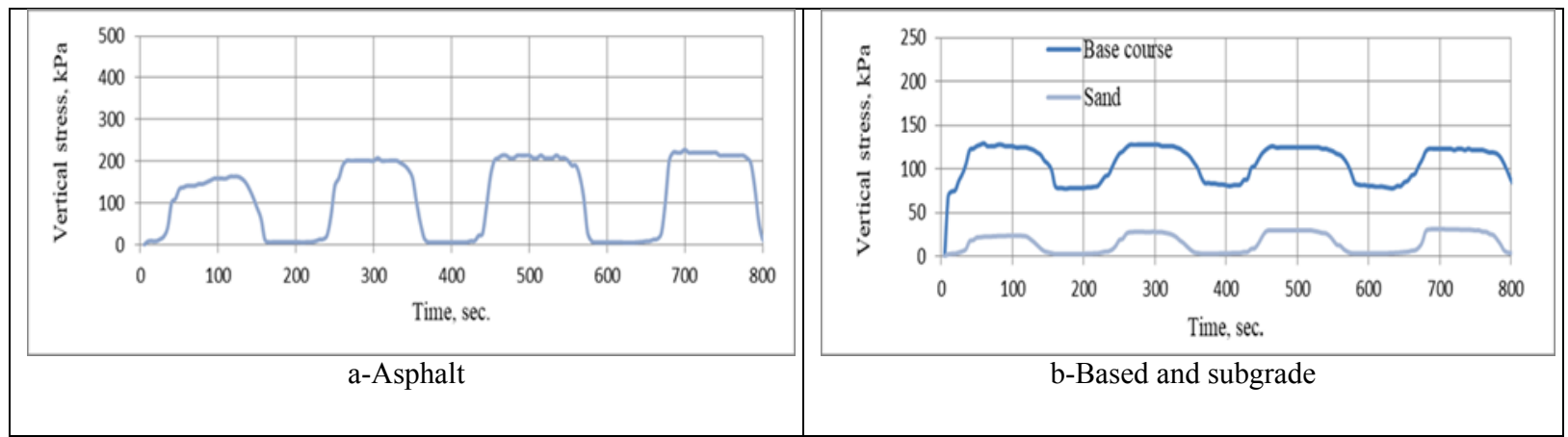

Figure 14: Variation of vertical stress in road layers under a frequency $0.5 \mathrm{~Hz}$ and load amplitude 15 $\mathrm{kN}$, geogrid in the midst of crushed stone layer

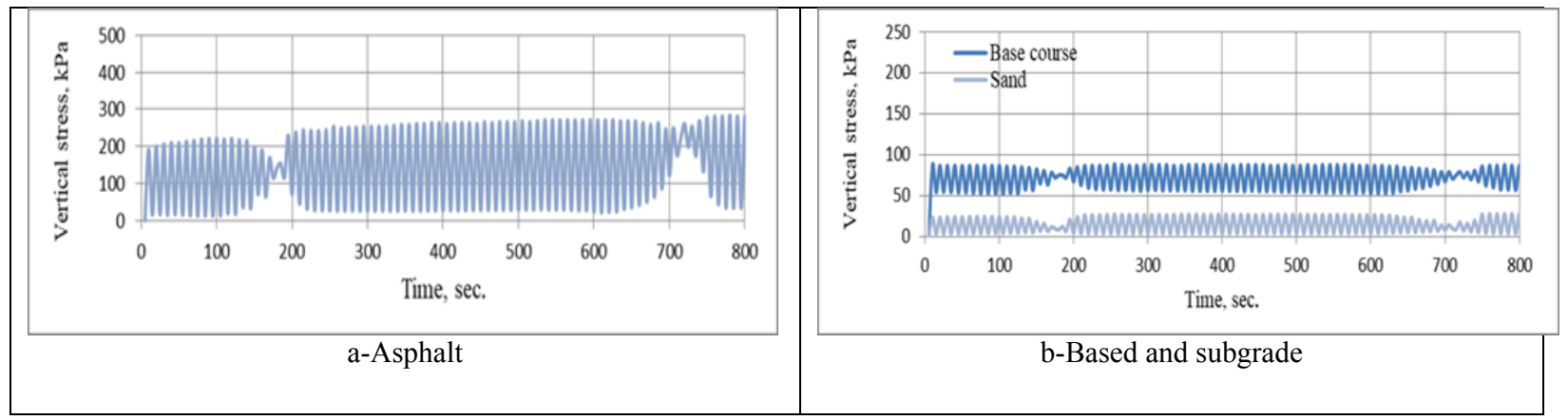

Figure 15: Variation of vertical stress in road layers under a frequency $1 \mathrm{~Hz}$ and load amplitude 15 $\mathrm{kN}$, geogrid in the middle of crushed stone layer

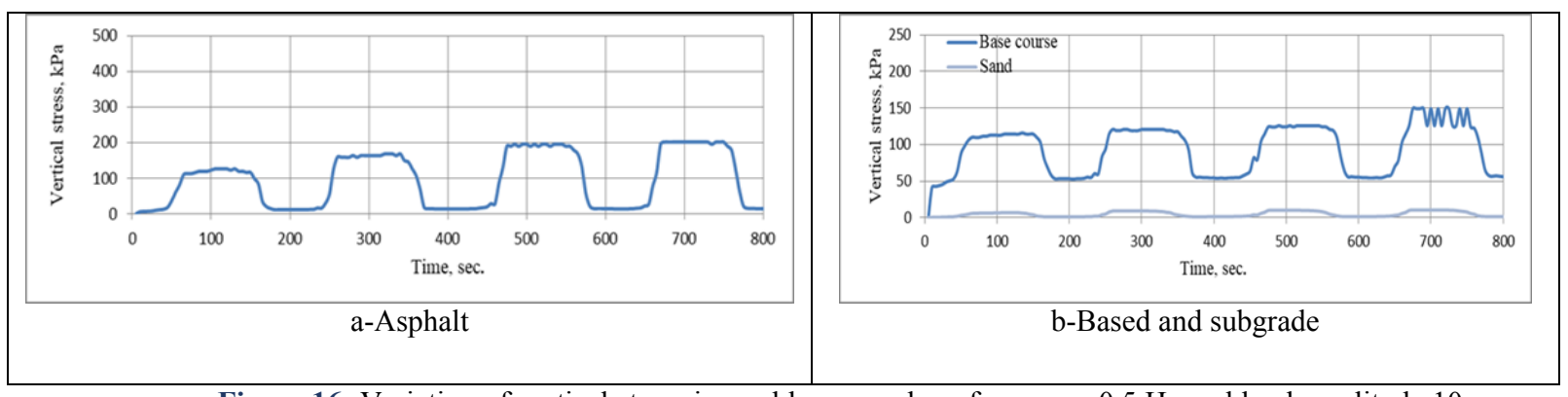

Figure 16: Variation of vertical stress in road layers under a frequency $0.5 \mathrm{~Hz}$ and load amplitude 10 $\mathrm{kN}$, geogrid between base course and subgrade

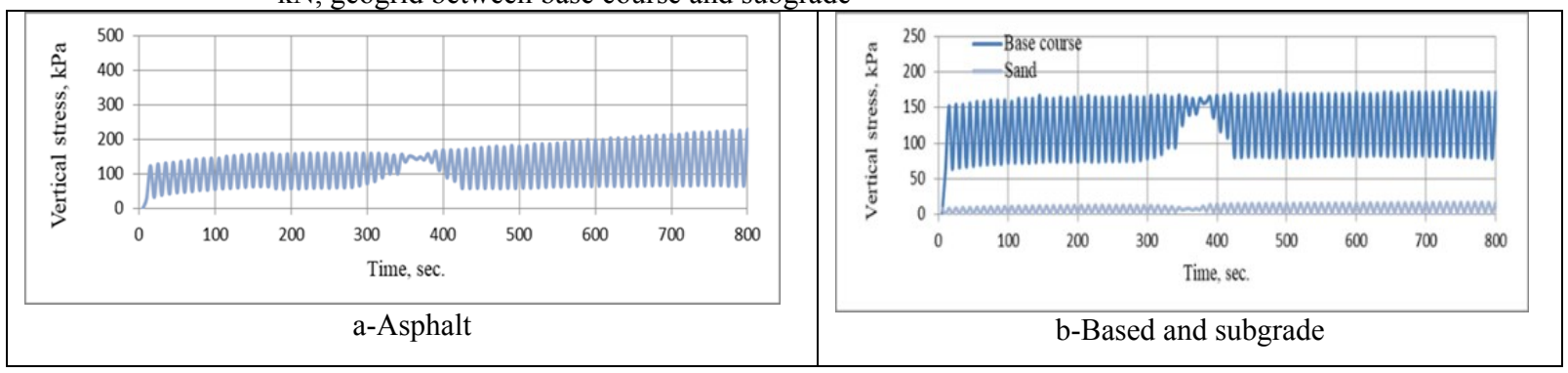

Figure 17: Variation of vertical stress in road layers under a frequency $1 \mathrm{~Hz}$ and load amplitude 10 $\mathrm{kN}$, geogrid between base course and subgrade 


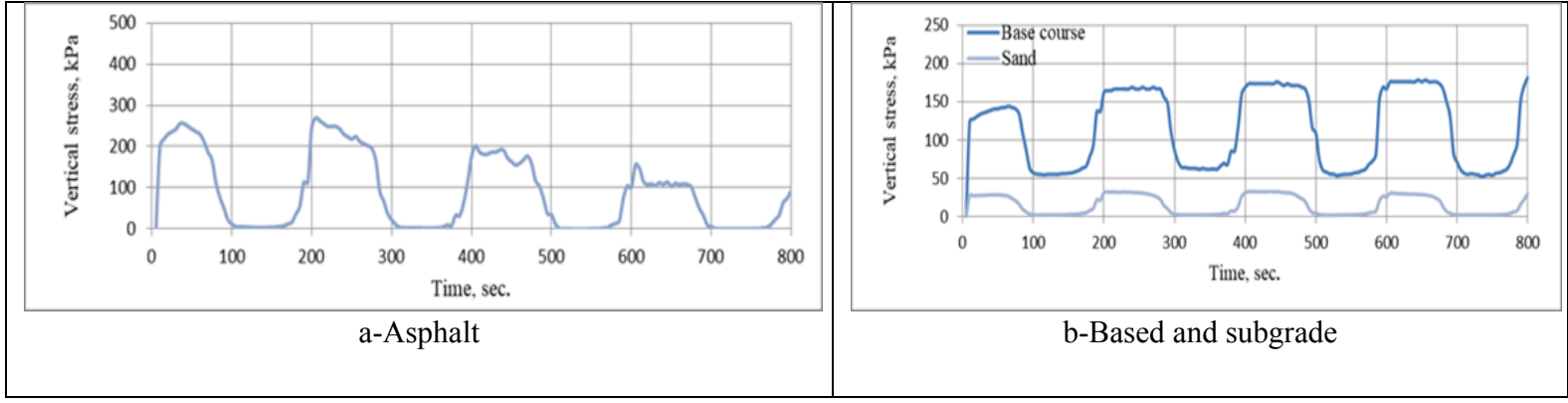

Figure 18: Variation of vertical stress in road layers under a frequency $0.5 \mathrm{~Hz}$ and load amplitude 15 $\mathrm{kN}$, geogrid between base course and subgrade

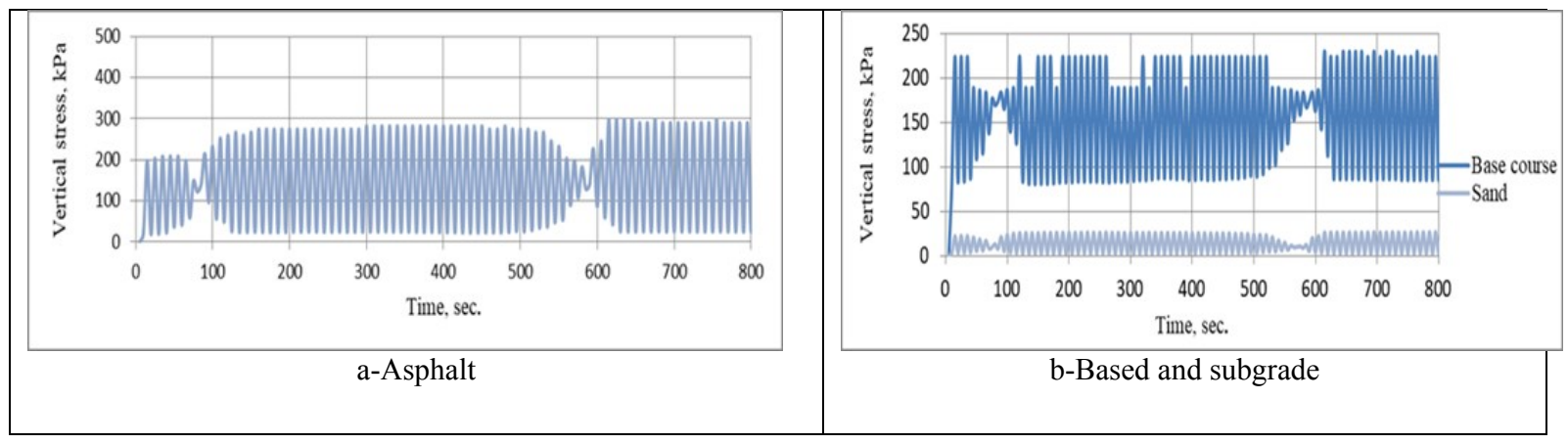

Figure 19: Variation of vertical stress in road layers under a frequency $1 \mathrm{~Hz}$ and load amplitude 15 $\mathrm{kN}$, geogrid between base course and subgrade

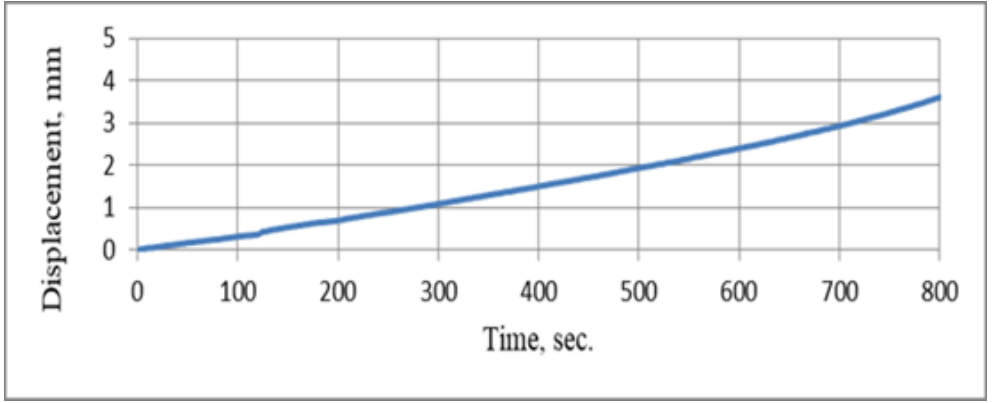

Figure 20: Variation of displacement in road layers under frequency $1 \mathrm{~Hz}$ and load capacity 1 ton

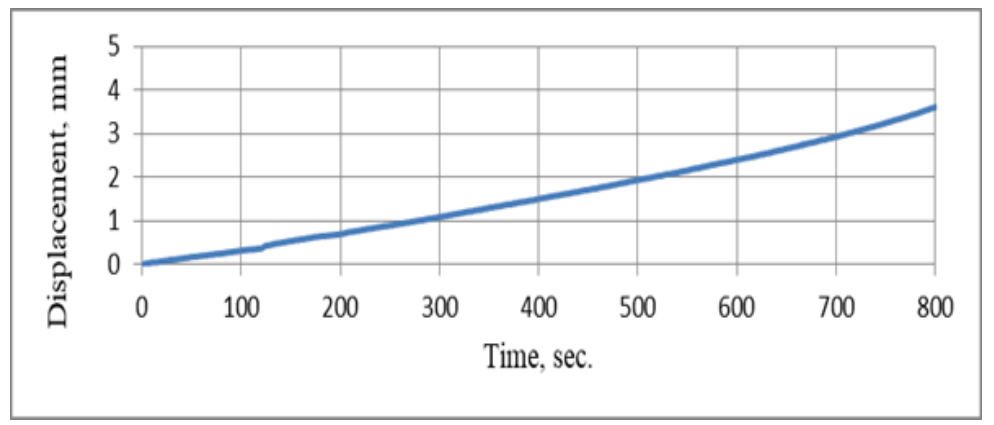

Figure 21: Variation of displacement in road layers under frequency $0.5 \mathrm{~Hz}$ and load capacity 1 ton

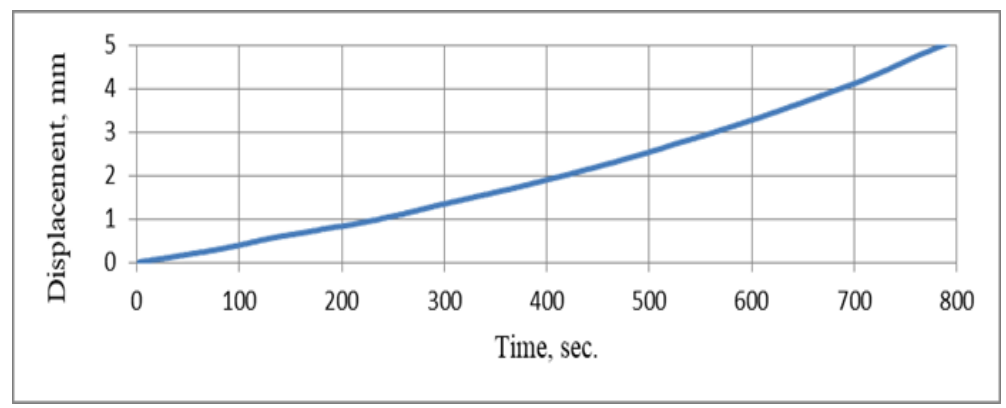

Figure 22: Variation of displacement in road layers under frequency $1 \mathrm{~Hz}$ and load capacity 1.5 ton 


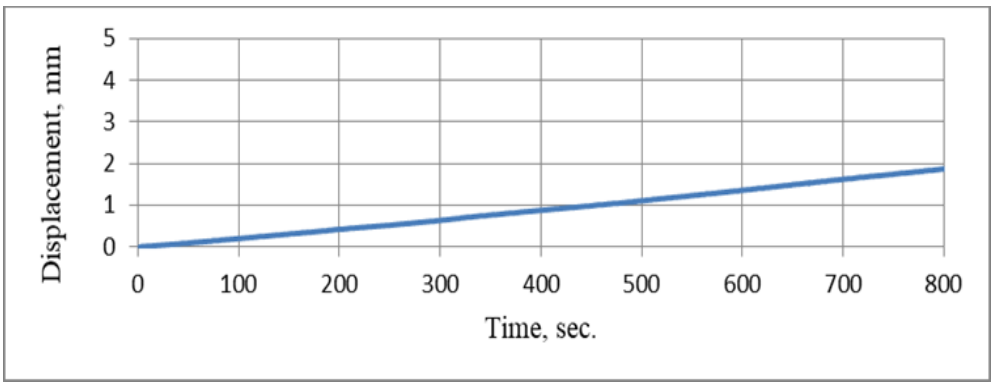

Figure 23: Variation of displacement in road layers under frequency $0.5 \mathrm{~Hz}$ and load capacity 1.5 ton

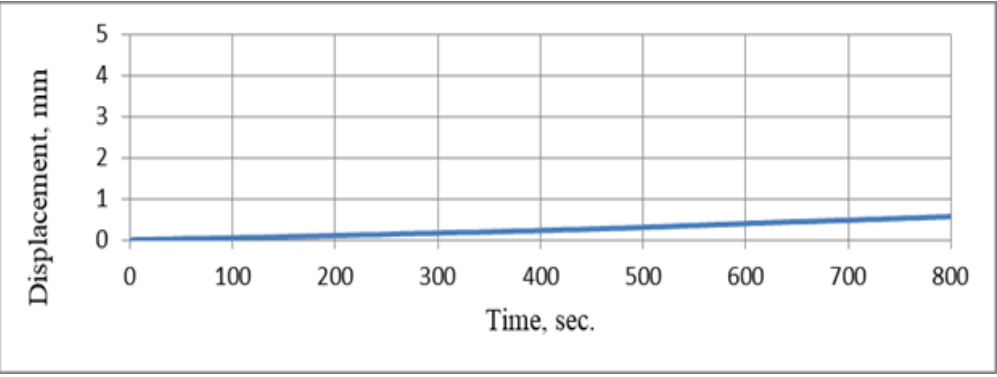

Figure 24: Variation of displacement in road layers under a frequency $0.5 \mathrm{~Hz}$ and load amplitude 10 $\mathrm{kN}$, geogrid at the middle of base layer

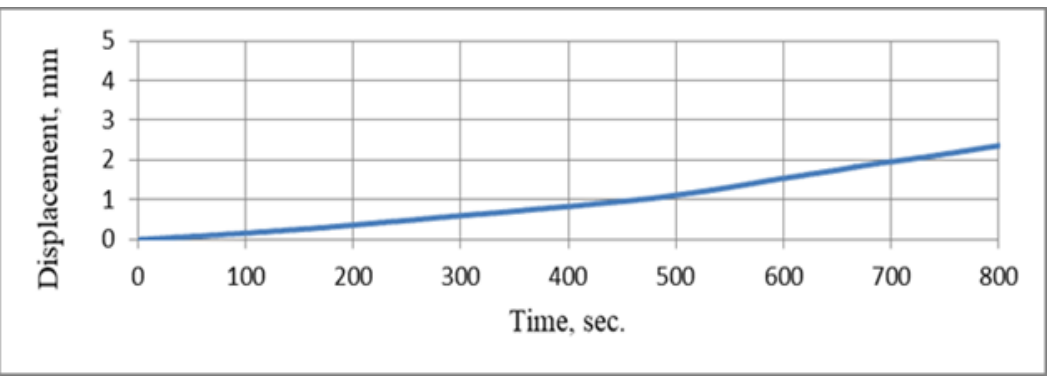

Figure 25: Variation of displacement in road layers under a frequency $1 \mathrm{~Hz}$ and load amplitude 10 $\mathrm{kN}$, geogrid in the midst of crushed stone layer

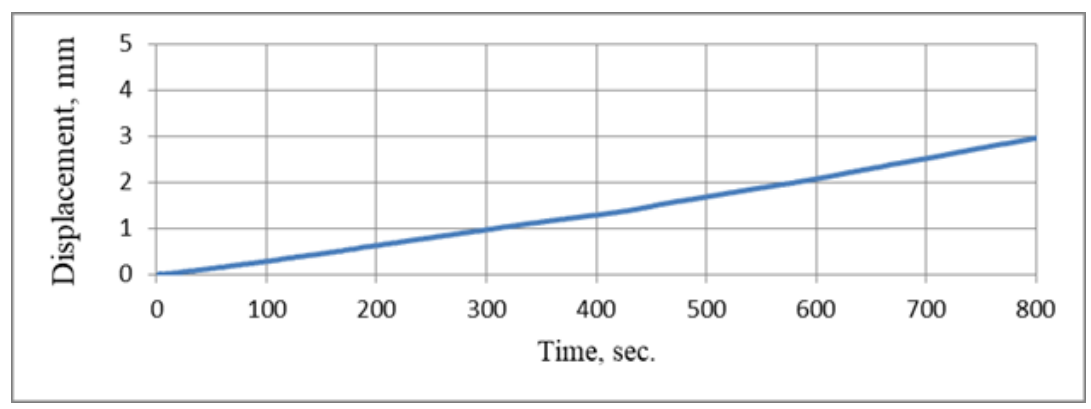

Figure 26: Variation of displacement in road layers under a frequency $0.5 \mathrm{~Hz}$ and load amplitude 15 $\mathrm{kN}$, geogrid in the midst of crushed stone layer

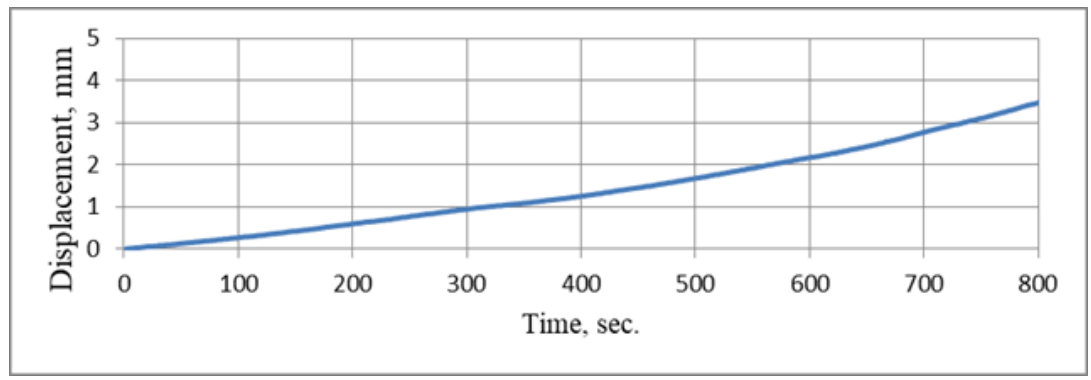

Figure 27: Variation of displacement in road layers under a frequency $1 \mathrm{~Hz}$ and load amplitude15 $\mathrm{kN}$, geogrid at the middle of base layer 


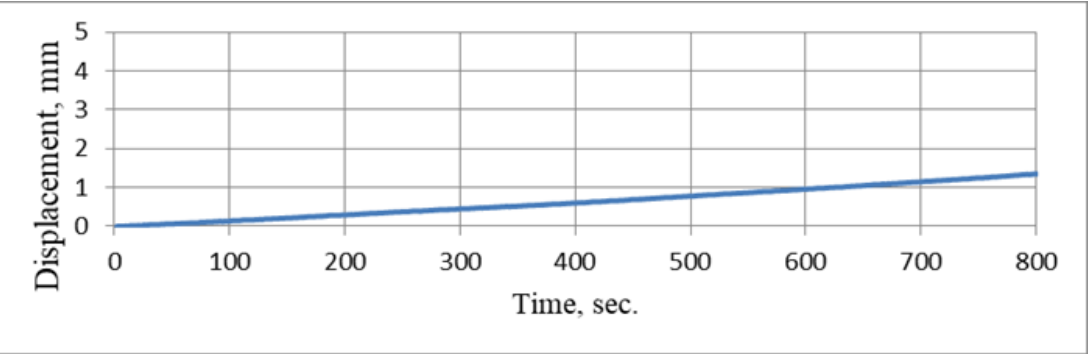

Figure 28: Variation of displacement in road layers under a frequency $0.5 \mathrm{~Hz}$ and load amplitude 10 $\mathrm{kN}$, geogrid between base course and subgrade

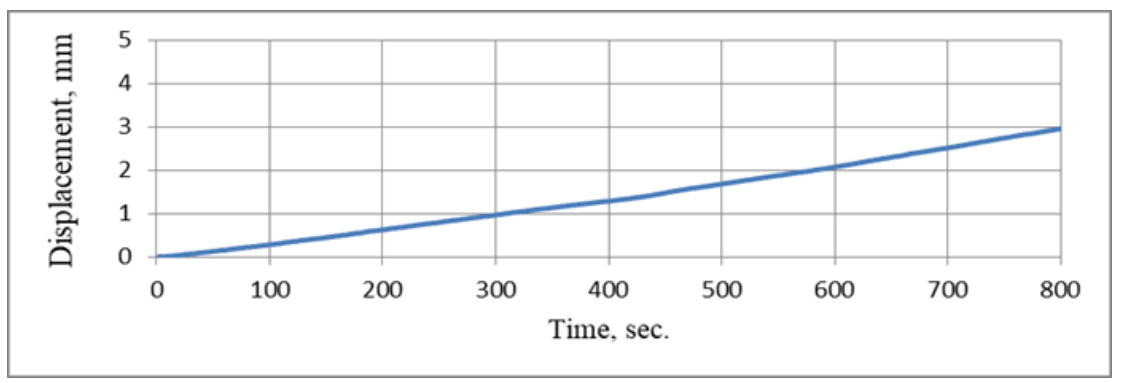

Figure 29: Variation of displacement in road layers under a frequency $1 \mathrm{~Hz}$ and load amplitude 10 $\mathrm{kN}$, geogrid between base course and subgrade

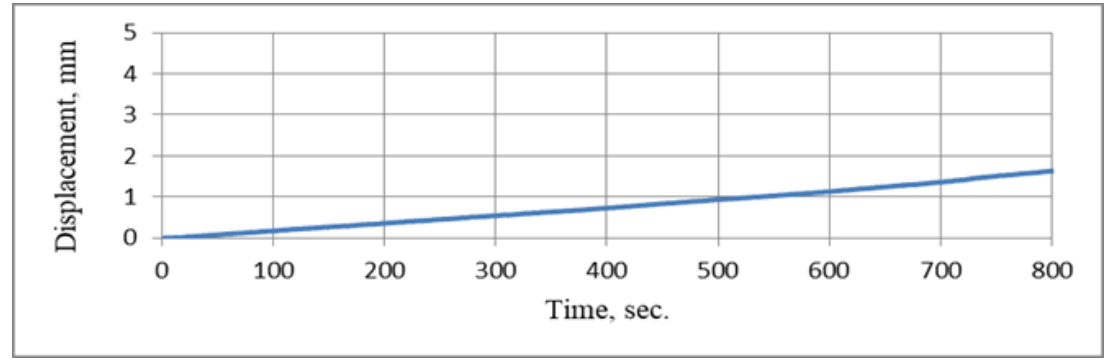

Figure 30: Variation of displacement in road layers under a frequency $0.5 \mathrm{~Hz}$ and load amplitude 15 $\mathrm{kN}$, geogrid between base course and subgrade

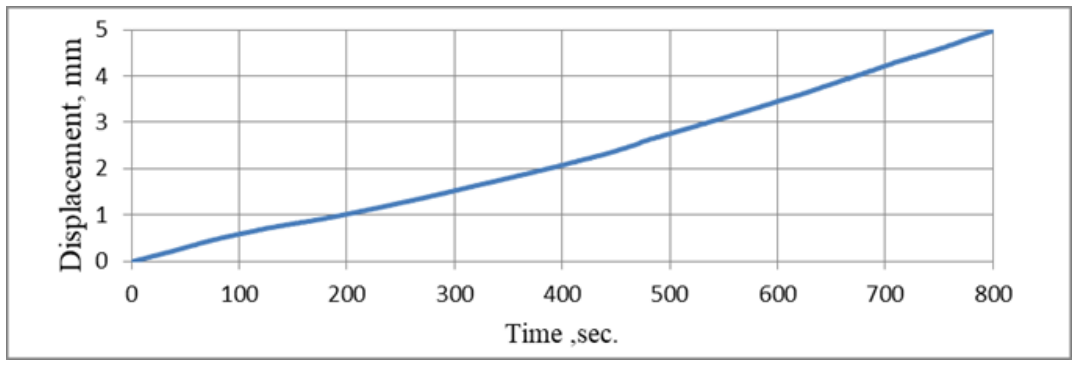

Figure 31: Variation of displacement in road layers under a frequency $1 \mathrm{~Hz}$ and load amplitude 15 $\mathrm{kN}$, geogrid between base course and subgrade

Table 1: Physical properties of asphalt cement

\begin{tabular}{cc}
\hline Test & Result \\
\hline Penetration $\left(25^{\circ} \mathrm{C}, 100 \mathrm{~g}, 5 \mathrm{sec}\right)$ & 47 \\
Ductility $\left(25^{\circ} \mathrm{C}, 5 \mathrm{~cm} / \mathrm{min}\right)$ & 110 \\
Softening point $($ Ring \& Ball $)$ & 53 \\
Flash and fire point & 261,264 \\
Loss on heating $\left(163^{\circ} \mathrm{C}, 50 \mathrm{gm}, 5 \mathrm{~h}\right) \%$ & 0.07 \\
Rotational Viscosity & $0.6425 @ 135^{\circ}$ \\
Specific gravity asphalt & $0.164 @ 165^{\circ} \mathrm{C}$ \\
\end{tabular}


Table 2: Summary of test results in the asphalt layer for models with SS2 type of geogrid

\begin{tabular}{|c|c|c|c|c|c|c|}
\hline Case & $\begin{array}{l}\text { Frequency } \\
\text { (Hz) }\end{array}$ & $\begin{array}{c}\text { Load } \\
\text { amplitude } \\
(\mathbf{k N})\end{array}$ & $\begin{array}{l}\text { Max. } \\
\text { stress } \\
(\mathbf{k P a})\end{array}$ & $\begin{array}{c}\text { Percent } \\
\text { change \% }\end{array}$ & $\begin{array}{c}\text { Max. } \\
\text { displacement } \\
(\mathrm{mm})\end{array}$ & $\begin{array}{l}\text { Percent } \\
\text { change }\end{array}$ \\
\hline Without geogrid & 0.5 & 10 & 332.6 & $\ldots \ldots$ & 3.61 & $\ldots \ldots$ \\
\hline Without geogrid & 1 & 10 & 283.2 & $\ldots .$. & 5.54 & $\ldots .$. \\
\hline Without geogrid & 0.5 & 15 & 386.0 & $\ldots \ldots$ & 1.87 & $\ldots \ldots$ \\
\hline Without geogrid & 1 & 15 & 435.7 & $\ldots \ldots$ & 5.15 & $\ldots \ldots$ \\
\hline $\begin{array}{l}\text { with geogrid in the } \\
\text { midst of base }\end{array}$ & 0.5 & 10 & 198.6 & 40.2 & 0.56 & 84.5 \\
\hline $\begin{array}{l}\text { with geogrid in the } \\
\text { midst of base }\end{array}$ & 1 & 10 & 216.6 & 23.5 & 2.34 & 57.9 \\
\hline $\begin{array}{l}\text { with geogrid in the } \\
\text { midst of base }\end{array}$ & 0.5 & 15 & 220.7 & 42.8 & 2.98 & 37.4 \\
\hline $\begin{array}{l}\text { with geogrid in the } \\
\text { midst of base }\end{array}$ & 1 & 15 & 281.3 & 35.4 & 3.48 & 32.4 \\
\hline $\begin{array}{l}\text { with geogrid on } \\
\text { sand }\end{array}$ & 0.5 & 10 & 201.3 & 39.4 & 1.35 & 62.7 \\
\hline $\begin{array}{l}\text { with geogrid on } \\
\text { sand }\end{array}$ & 1 & 10 & 225.3 & 20.4 & 2.96 & 46.7 \\
\hline $\begin{array}{l}\text { with geogrid on } \\
\text { sand }\end{array}$ & 0.5 & 15 & 248.8 & 35.5 & 1.64 & 12.7 \\
\hline $\begin{array}{l}\text { with geogrid on } \\
\text { sand }\end{array}$ & 1 & 15 & 298.1 & 31.5 & 4.98 & 3.2 \\
\hline
\end{tabular}

\section{Conclusion}

By performing laboratory tests on models with different variables under the influence of dynamic loads, the following conclusions can be drawn.

1. In the case of a reinforcing layer at the middle of base course layer, the stress and vertical displacement decrease with increase in frequency and load amplitudes.

2. When laying the geogrid between the base course and subgrade, a lower decrease in the stress and vertical displacement could be obtained with the increase in frequency and loads.

\section{Author Contribution}

All authors contributed equally to this work.

\section{Funding}

This research received no specific grant from any funding agency in the public, commercial, or not-for-profit sectors.

\section{Data Availability Statement}

The data that support the findings of this study are available on request from the corresponding author.

\section{Conflicts of Interest}

The authors declare that there is no conflict of interest.

\section{References}

[1] B.M. Das, and E.C. Shin, "Strip foundation on geogrid-reinforced clay: behavior under cyclic loading." Geotextiles and Geomembranes, 13(10), pp. 657-666, 1998.

[2] Q. Chen, M. Abu-Farsakh, R, Sharma, X. Zhang, "Laboratory investigation of behavior of foundations on geosyntheticreinforced clayey soil". Transportation Research Record: Journal of the Transportation Research Board, pp. 28-38, 2007.

[3] H. Siriwardane, R. Gondle,\&K. Bora, “Analysis of flexible pavements reinforced with geogrids”, Geotechnical and Geological Engineering, vol. 28, No. 3, pp. 287-297, 2010.

[4] E.R.Sujatha, B. J. Vignesh, R. Vijay, "Improving the strength of sub grade using geo-grids", International Journal of Emerging Trends in Engineering and Development, vol. 2, Issue 2, 2012.

[5] P. S. Kumar, and R. Rajkumar, "Effect of geotextile on CBR strength of unpaved road with soft subgrade" Electronic Journal of Geotechnical Engineering (EJGE), 17, pp. 1355 - 1363, 2012. 
[6] L. Zheng, Y. H. Lin, W. Wan-peng, and C. Ping, "Dynamic stress and deformation of a layered road structure under vehicle traffic loads: Experimental measurements and numerical calculations", Soil Dynamics and Earthquake Engineering, vol. 39, pp. 100-112, 2012.

[7] A. Graziani, E. Pasquini, G. Ferrotti, A. Virgili,and F. Canestrari, "Structural response of grid-reinforced bituminous pavements "Materials and Structures, 47(8): pp. 1391-1408, 2014.

[8] A. N. Najim, M.Y. Fattah, M. K. M. Al-Recaby, "Cyclic settlement of footings of different shapes resting on clayey soil", Eng. and Tech. Journal, 38(3A), pp. 465-477,2020.

[9] Asphalt Institute, “Superpave Mix Design SP-2", Third Edition, Lexington, KY, USA, 2003.

[10] A. I. K.Al-Utabi, "An approach in improving unpaved roads overlying soft clay soils using geogrid", M.Sc. thesis, College of Engineering, Al-Mustansiriyah University, Iraq, 2011.

[11] Z. T. Teama, "Suitability of dune sands subgrade beneath flexible pavement structure under repeated loads", M.Sc., thesis, College of Engineering, Al-Mustansiriyah University, Iraq, 2014.

[12] K. Reddy, "Influence of subgrade condition on rutting in flexible pavements- an experimental investigation", International Journal of Civil Engineering and Technology, vol. 4, Issue 3, pp. 30-37, 2013.

[13] M. F. Aswad, "Behavior of improved railway ballast overlying clay using geogrid", Ph.D. thesis, Building and Construction Engineering Department, University of Technology, Baghdad, Iraq, 2016.

[14] B.Leshchinsky, and H. I. Ling "Numerical modeling of behavior of railway ballasted structure with geocell confinement," Geotextiles and Geomembranes Journal, 36, pp. 33-43, 2013.

[15] M. Y. Fattah, M. R. Mahmood, M. F. Aswad, "Stress distribution from railway track over geogrid reinforced ballast underlain by Clay", Earthquake Engineering and Engineering Vibration, vol. 18, no. 1, pp. 77-93, Springer, 2019.

[16] M. Y. Fattah, M. J. Al-Mosawi, A. F. I Al-Ameri, "Stresses and pore water pressure induced by machine foundation on saturated sand", Ocean Engineering, vol. 146, pp. 268-281, Elsevier, 2017.

[17] R. E. Hamdi, M. Y. Fattah, M. F. Aswad, "Studying the settlement of backfill sandy soil behind retaining wall under dynamic loads", Eng. and Tech. Journal, vol. 38, part A (2020), no. 07, pp. 992-1000, 2020.

[18] M. Y. Fattah, N. M. Salim, M. S. Ismaiel, "Influence of geogrid reinforced loose sand in transfer of dynamic loading to underground structure", Eng. and Tech. Journal, vol. 34,part (A), no. 11, pp. 1915-1927, 2016. 